\title{
A Preliminary Report of Percutaneous Craniofacial Osteoplasty in a Rat Calvarium
}

\author{
William J. Parkes, MD \\ Thomas Jefferson University \\ Jewel Greywoode, MD \\ Thomas Jefferson University \\ Brian J. O'Hara, MD \\ Jefferson Medical College of Thomas Jefferson University, Philadelphia, PA \\ Ryan N. Heffelfinger, MD

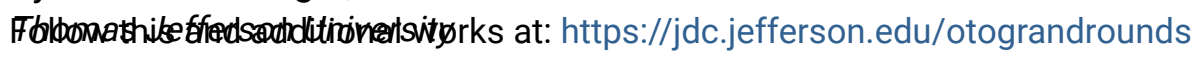

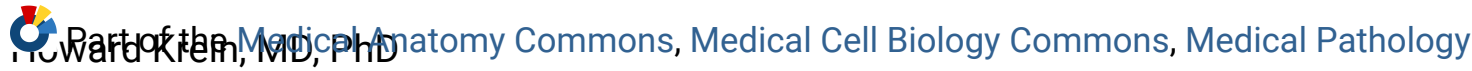

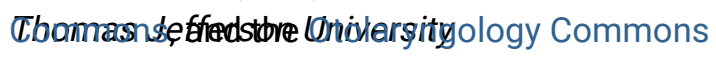 \\ Let us know how access to this document benefits you
}

\section{Recommended Citation}

Parkes, MD, William J.; Greywoode, MD, Jewel; O'Hara, MD, Brian J.; Heffelfinger, MD, Ryan N.; and Krein, MD, PhD, Howard, "A Preliminary Report of Percutaneous Craniofacial Osteoplasty in a Rat Calvarium" (2013). Department of Otolaryngology - Head and Neck Surgery Presentations and Grand Rounds. Presentation 16.

https://jdc.jefferson.edu/otograndrounds/16

This Article is brought to you for free and open access by the Jefferson Digital Commons. The Jefferson Digital Commons is a service of Thomas Jefferson University's Center for Teaching and Learning (CTL). The Commons is a showcase for Jefferson books and journals, peer-reviewed scholarly publications, unique historical collections from the University archives, and teaching tools. The Jefferson Digital Commons allows researchers and interested readers anywhere in the world to learn about and keep up to date with Jefferson scholarship. This article has been accepted for inclusion in Department of Otolaryngology - Head and Neck Surgery Presentations and Grand Rounds by an authorized administrator of the Jefferson Digital Commons. For more information, please contact:

JeffersonDigitalCommons@jefferson.edu. 


\section{A Preliminary Report of Percutaneous Graniofacial Osteoplasty in a Rat Galuavium}

William J Parkes, MD¹; Jewel Greywoode, MD¹; Brian J O'Hara, MD²; Ryan N Heffelfinger, MD¹; Howard Krein, MD, PhD1 Thomas Jefferson University Departments of ${ }^{1}$ Otolaryngology- Head \& Neck Surgery and ${ }^{2}$ Pathology, Anatomy \& Cell Biology

ABSTRMAT

Objective: To evaluate the potential for njectable, permanent bone

biocompatbility and bioactivity subperiosteal hydroxylapatite (Radiesse) deposition in a rat mode

Methods: Fourteen adult Sprague Dawley rats were injecied in the parietal

skul with hydroxylapatite $(n=10)$ or a carrier gel control $(n=4)$, using a
subperiosteal injection technique on the right and a subcutaneous injection technique on the left. At 1,3 , and 6
to months, 3 rats ( 1 negative control, 2 variables) were sacrificed. At 12 months, the remaining 5 rats were sacrificed. After each harvest, the and polarized microscopy.

Results: The inflammatory response was Imited in all specimens. Injectables injection. New bone formation whe seen when the injection was located deep to a disrupted periosteum The odd of new bone formation was 48.949 times higher $(95 \% \mathrm{Cl}(2.637,3759.961), \mathrm{p}=$ 0.002 ) with subperiosteal hydroxylapatite injections compared to all other injectable

Conclusion: This preliminary report of subperiosteal hydroxylapatite (Radiesse) biocompatibility of injectable hydroxylapatite at the bony interface anc suggests the

BONTAB William J Parkes, MD
Email: william.parkes@jefferson.edu
Phone: 215-498-2493

\section{NITRODUGTION}

Presently, calcium phosphate cements (CPC), such as hydroxylapatite (HA), are commonly used for the characteristics of CPC include customizability, isotherm setting, biocompatibility, and bioactivity (resorption is countered by new bone replacement). ${ }^{1}$ Because of the (5) is required to use CPC eflectively, and thus the application of CPC is trauma. However, facial plastic surgeons are often faced with smaller craniofacial deformities that are of aesthetic concern to the patient but do not warrant the morbidity of open surgery. Examples would include relatively minor was designed to examine the biologic characteristics of injectable HA when interfaced with bone.

\section{METHOS}

Fourteen adult Sprague Dawley rats were injected in the parietal skull wh $0.2 \mathrm{ml}$ of $\mathrm{HA}(\mathrm{n}=10)$ or a carrier gel control $(n=4)$. needle in a subcutaneous plane. On the right side of the calvarium, a 20-gauge needle was first employed to elevate the periosteum, and then a 23-gauge needle was used to inject the material drectly on to the underlying

Animals were subsequently sacrificed at 4 time and calvaria were harvested for histologic analysis. Eac of the first 3 harvests included 2 rats from the HA group and 1 negative control from the carrier gel group. The well as the remaining 4 rats from the HA group. All Under low power magnification, the injectables were located and the surrounding tissue was examined. Pxamining and comparing separate sas conirmed by and carrier gel ex vivo (Figure 1). Polarized of the HA was used to distinguish new (woven) bone from mature (lamellar) bone.

Odds ratios, $p$ values and $95 \%$ confidence Intervals (Cl) were calculated using Fisher's conditional considered significant.

\section{RESULIS}

Histologic data are summarized in Table 1. While multinucleated giant cells were often present (Figure 2), only minimal fibrosis was noted in the specimens. Seven 2 carrier, $5 \mathrm{HA}$ ) out of 13 "subperiosteal" injections wer
lound to be deep to a disrupted periosteum, while the remaining 6 were noted to be in the subcutaneous layer with an hact pendosed beneath. OP note, HA spherules 12 and at both injection sites for specimen 13

Reactive bone was not seen in the absence of periosteal disruption. In 1 of 2 rats with successful subperiosteal carrier injections, reactive bone was present at the time of harvest. This rat, specimen 7 , was observed with subperiosteal HA injections in 4 out of 5 rats- specimen 2 from the 1 month harvest (Figure 4 , specimen 5 from the 3 month harvest, and specimens 12 and 14 from the 12 month harvest. Interestingly, mature lamellar bone was seen above hie HA sphent

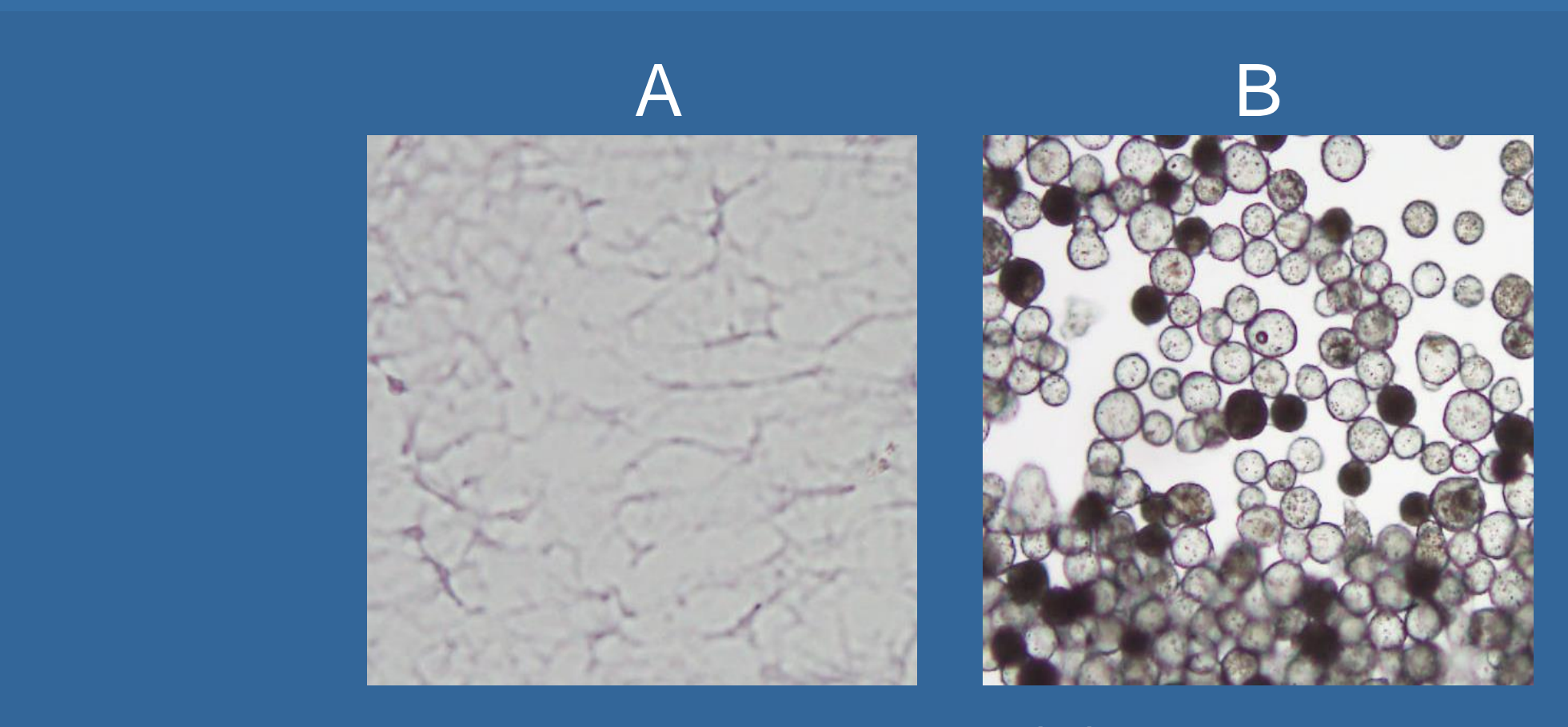

Figure 1. Amorphous carrier gel (A) and hydroxylapatite

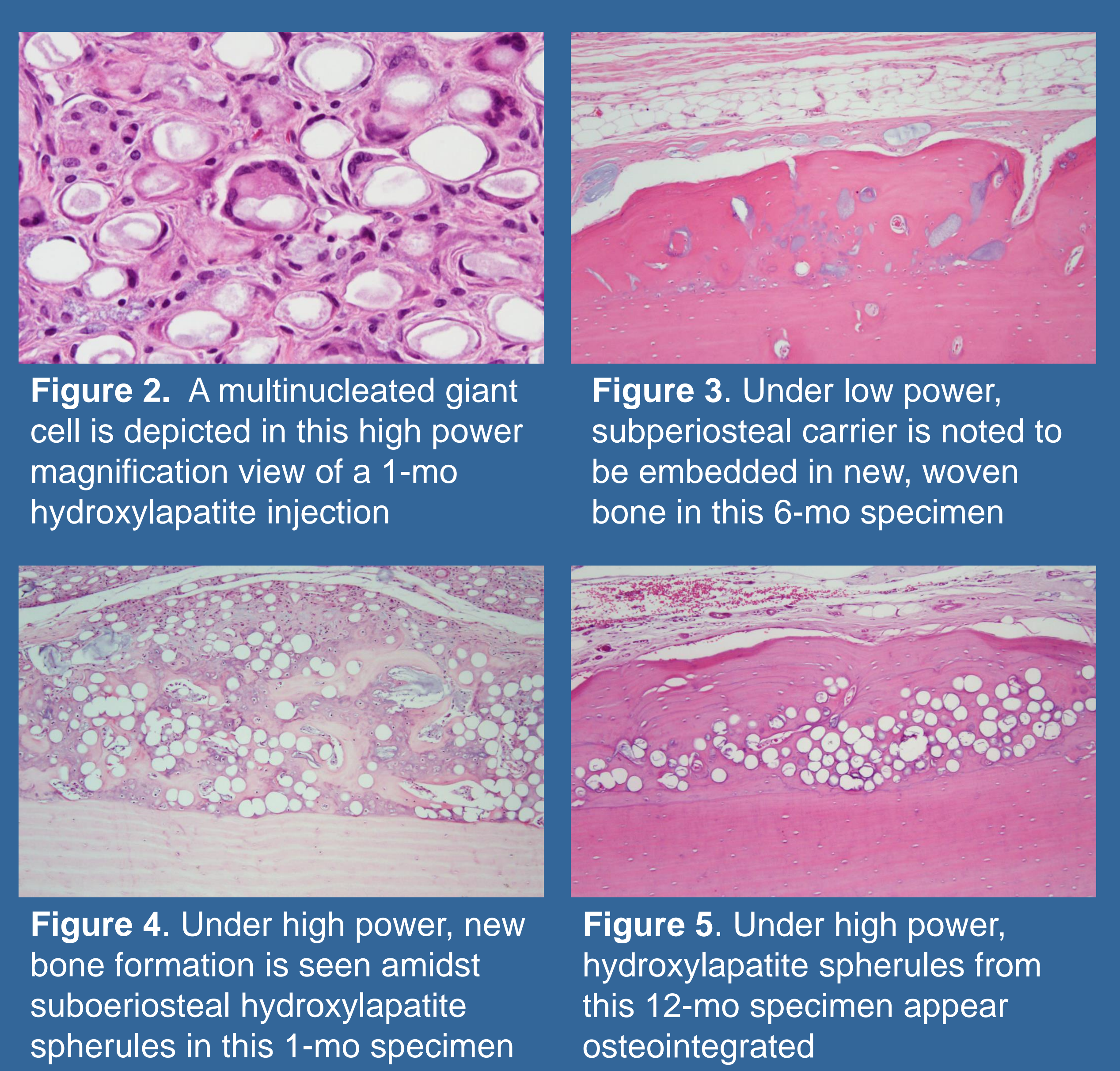

\section{RESULIS}

In an attempt to analyze the effect of the injection lane (subcutaneous vs subperiosteal) and the injectab (carrier vs $\mathrm{HA}$ ) on new bone formation, histologic data miections that were intended to be subperiosteal but were found to be subcutaneous on histologic review were

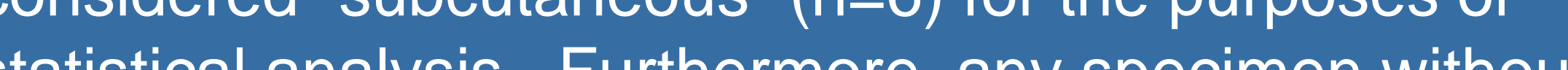
en identifiable iniectable (subcutaneous injection site in specimen 12 and both sites in specimen 13) were excluded.

The odd of new bone formation in the

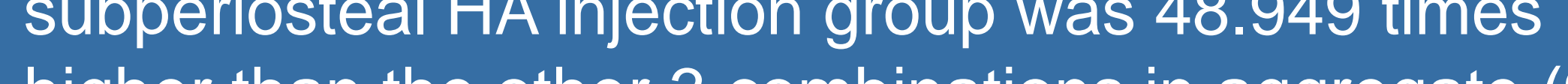
$\mathrm{Cl}(2.637,3759.961), p=0.002)$. The marrinal effect subperiosteal injection was also significant, but a discrete odds ratio could not be computed due to the zero-count cells in the subcutaneous groups $(95 \% \mathrm{Cl}(4.068$, infinity), $p<0.001)$. The marginal effect of $H A$, however
was not significant.

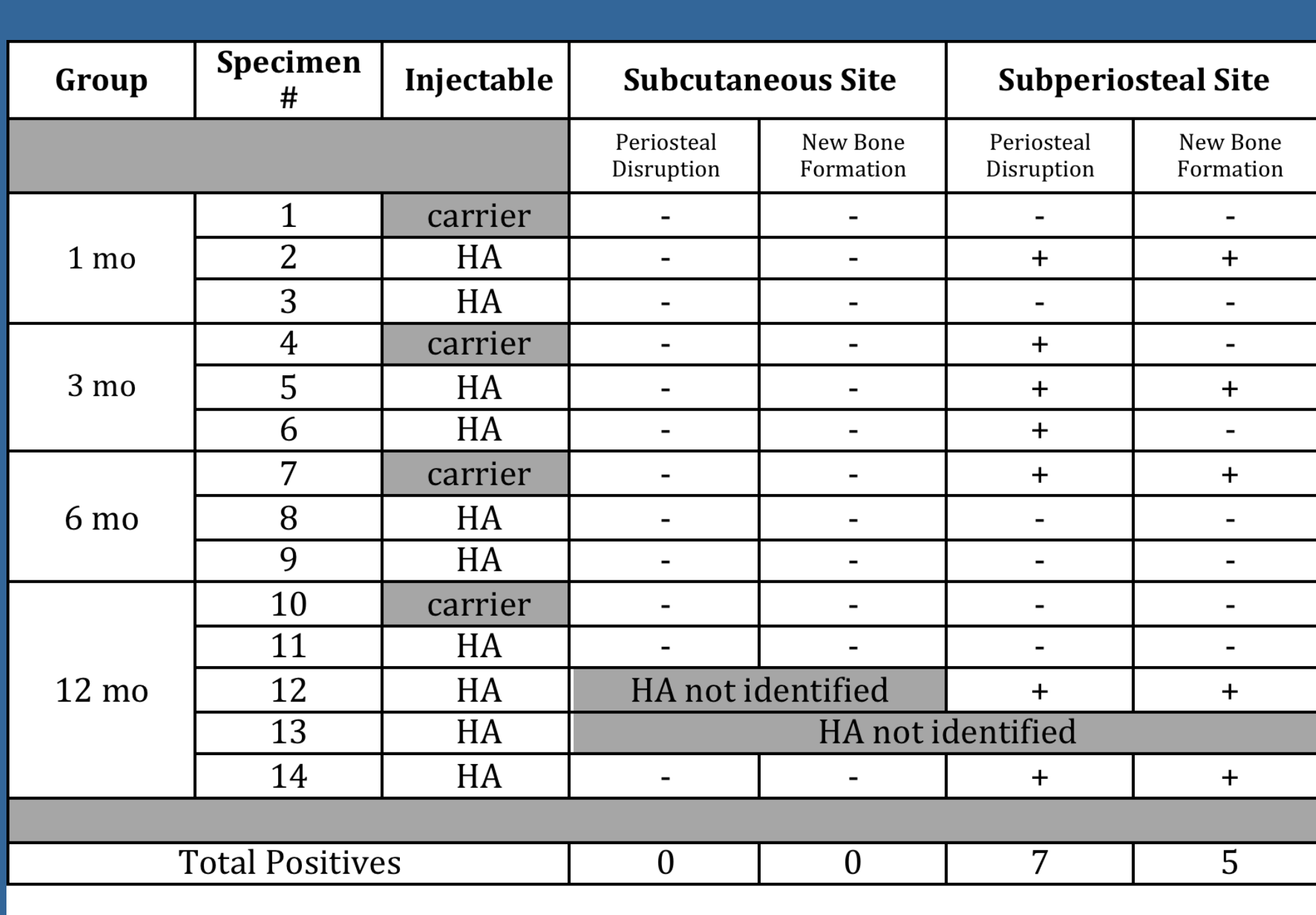

Table 1. Summary of binary histologic data. The
presence of periosteal lisruplition and new bone formation
is indicated with a (+). HA $=$ hydroxylapatite (Radiesse)

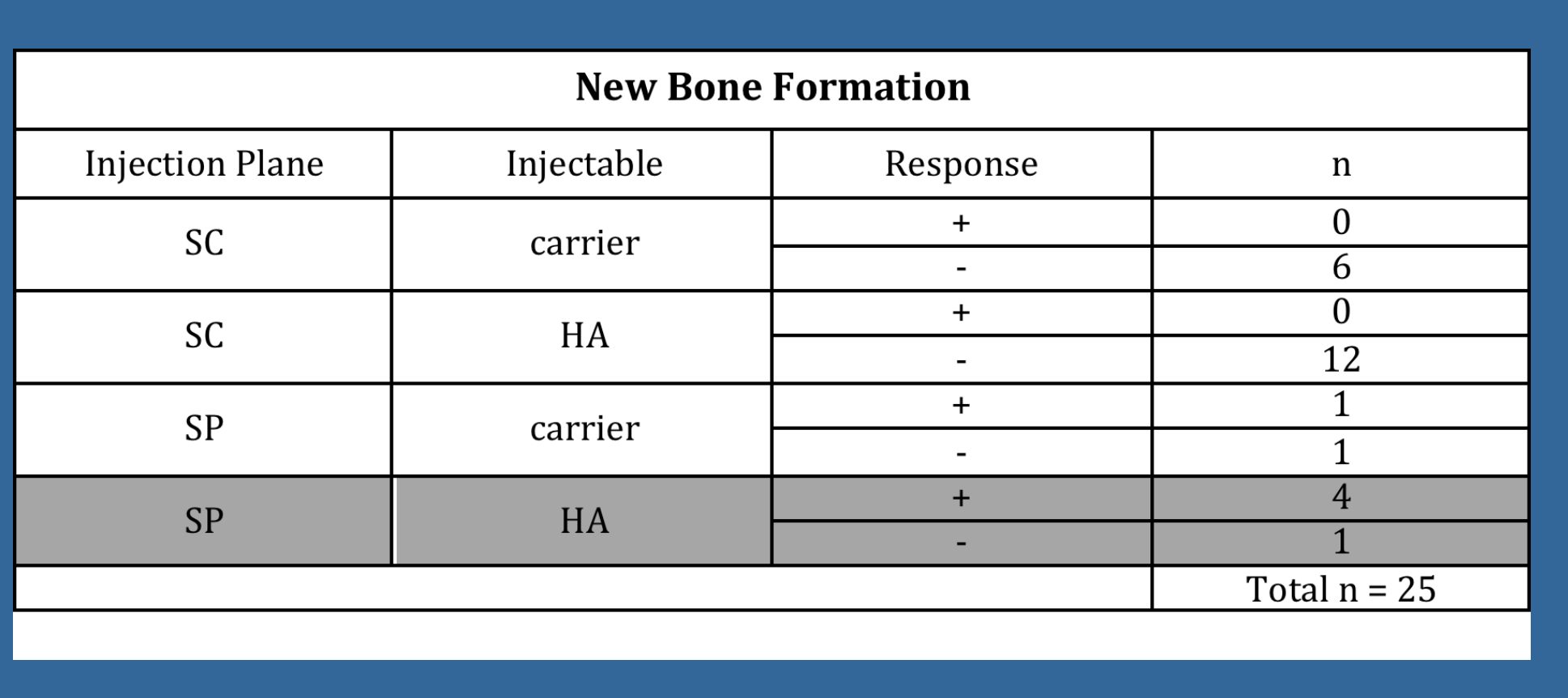
Table 2. Summary of binary data for rate of new bone
formation, grouped by all combinations of injection plane
and injectable. SC=subcutaneous, $S P=$ subperiosteal,

\section{DISAISSTOK}

Minor deformities of the craniofacial skeleton can be quite bothersome aesthetically to patients. Radiesse biologic constituent, HA, has been used for over 2 decades In other formulations for open craniofacial reconstruction.? FDA-approved for the treatment of HIV-related lipoatrophy established in facial plastic surgery for soft tissue augmentation. 3,4 Over the years, various studies $h$ ave confirmed its safety, longevity and bioactivity (specifically the stimulation of new collagen deposition) when injected subcutaneously. . $^{-7}$ Not surprisingly, off label uses of To our knowledge, no one to date has exarmined tife We have now shown that Radiesse is biocompatible and long-lasting subperiosteally. In designing the study, we did could triger osteoactivity and therefore confound results. We attempted to control for this with the carrier only injections; hypothesizing that new bone formation would be either absent or less pronounced without $H A$.

Unforinately, our technique for periosteal disruption was only successiul $54 \%$ of the time. Consequently, the
numbers for truly subperiosteal $\mathrm{HA}$ and carrier iniections were simply too low to demonstrate a statistically significan difierence in the rate of new bone formation between the two. Notably, though, the odd of new bone formation in the subperiosieal $H A$ injection group was significantly higher plane and iniectable. We were also able to show-that the plane of injection seems to be critical in any effort to induce osteoactivity as none of the subcutaneous injections resulted in new bone formation. Lastly, our observations suggest that, regardless of the mechanism triggering new
bone formation, injectable HA can be osteointegrated.

Refinements in the technique for subperiosteal injection are clearly necessary, and further study on a larger
scale is warranted to better elucidate the stimulus for the osteoactivity we observed histologically.

BEFERENGES

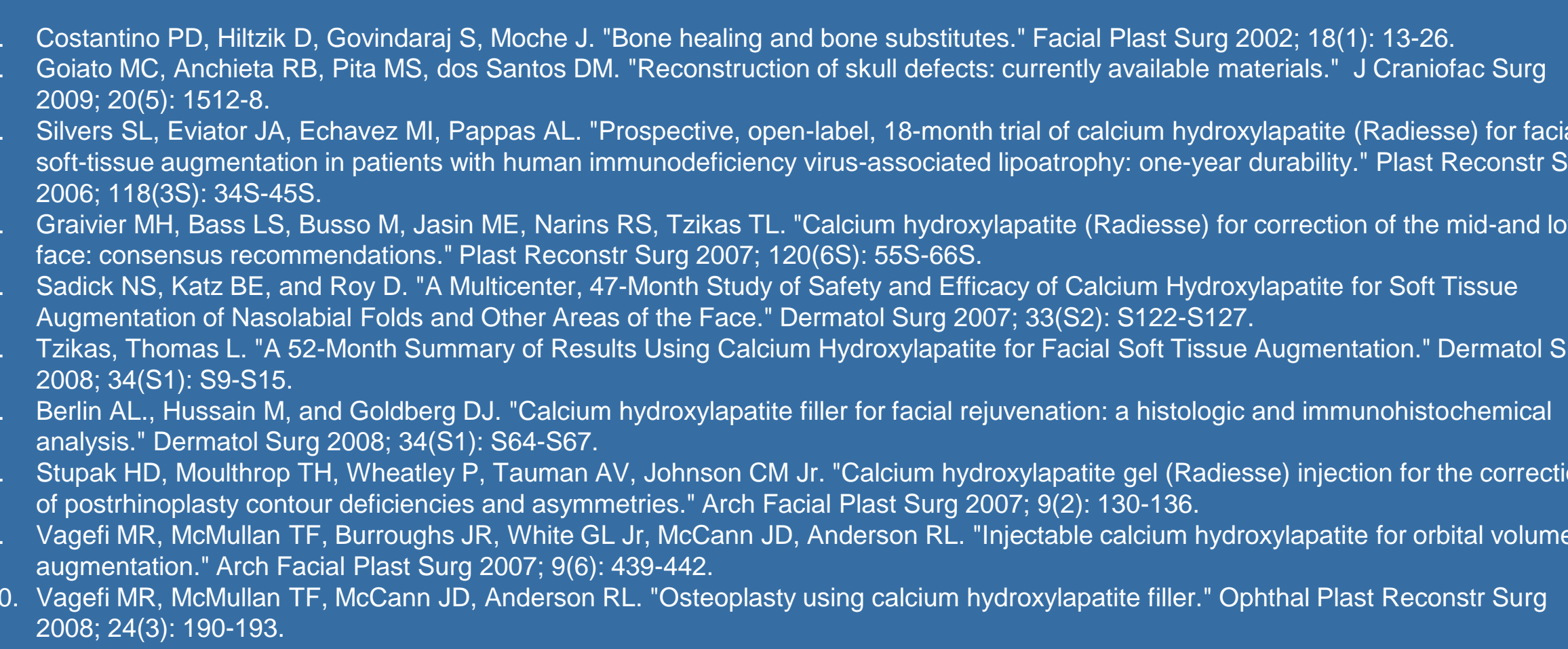

